\title{
Principles of Educational Outreach ('Academic Detailing') to Improve Clinical Decision Making
}

\section{Citation}

Soumerai, Stephen B. 1990. "Principles of Educational Outreach ('Academic Detailing') to Improve Clinical Decision Making." JAMA: The Journal of the American Medical Association 263 (4) (January 26): 549. doi:10.1001/jama.1990.03440040088034.

\section{Published Version}

doi:10.1001/jama.1990.03440040088034

\section{Permanent link}

http://nrs.harvard.edu/urn-3:HUL.InstRepos:32692212

\section{Terms of Use}

This article was downloaded from Harvard University's DASH repository, and is made available under the terms and conditions applicable to Other Posted Material, as set forth at http:// nrs.harvard.edu/urn-3:HUL.InstRepos:dash.current.terms-of-use\#LAA

\section{Share Your Story}

The Harvard community has made this article openly available.

Please share how this access benefits you. Submit a story.

Accessibility 


\title{
Principles of Educational Outreach ('Academic Detailing') to Improve Clinical Decision Making
}

\author{
Stephen B. Soumerai, ScD, Jerry Avorn, MD
}

With the efficacy and costs of medications rising rapidly, it is increasingly important to ensure that drugs be prescribed as rationally as possible. Yet, physicians' choices of drugs frequently fall short of the ideal of precise and costeffective decision making. Evidence indicates that such decisions can be improved in a variety of ways. A number of theories and principles of communication and behavior change can be found that underlie the success of pharmaceutical manufacturers in influencing prescribing practices. Based on this behavioral science and several field trials, it is possible to define the theory and practice of methods to improve physicians' clinical decision making to enhance the quality and cost-effectiveness of care. Some of the most important techniques of such "academic detailing" include (1) conducting interviews to investigate baseline knowledge and motivations for current prescribing patterns, (2) focusing programs on specific categories of physicians as well as on their opinion leaders, (3) defining clear educational and behavioral objectives, (4) establishing credibility through a respected organizational identity, referencing authoritative and unbiased sources of information, and presenting both sides of controversial issues, (5) stimulating active physician participation in educational interactions, (6) using concise graphic educational materials, (7) highlighting and repeating the essential messages, and (8) providing positive reinforcement of improved practices in follow-up visits. Used by the nonprofit sector, the above techniques have been shown to reduce inappropriate prescribing as well as unnecessary health care expenditures.

(JAMA. 1990;263:549-556)

THE HIGH cost of medical care and increasing concern about appropriate use of medical technology have resulted in a new wave of interest in how physicians can be encouraged to make more accurate and cost-effective clinical deci-

From the Program for the Analysis of Clinical Strate gies, Department of Social Medicine, Harvard Medical School and Beth Israel Hospital, Boston, Mass.

Reprint requests to Harvard Medical School, 643 Huntington Ave, Boston, MA 02115 (Dr Soumerai) sions. Some efforts have emphasized restrictions and economic disincentives, but evidence is emerging that in some applications such strategies may threaten the quality of care at least as much as they reduce expenditures. ${ }^{1,2}$ Continuing education has received much less attention as a means of behavior change, perhaps because it often is ineffective in this regard. ${ }^{3}$

University-based educational out- reach (sometimes known as "public interest detailing" or "academic detailing") is a newer approach that has been evaluated as part of a four-state randomized, controlled trial. ${ }^{47}$ Prescribing problems that could be targeted by such approaches include use of drugs with low benefit/risk ratios when safer alternatives are available, use of ineffective or marginal therapies for treatable conditions, use of excessive numbers of medications in vulnerable populations (eg, children and the elderly), use of high-cost agents when less expensive medications would work as well, and underuse of effective agents for major illnesses (eg, hypertension in the elderly)." In one study of educational outreach, two brief visits to physicians by clinical pharmacists trained in effective techniques of communication and persuasion as well as pharmacotherapy were found to reduce inappropriate prescribing of cerebral vasodilators, cephalexin, and propoxyphene by $14 \%$ in comparison with controls $(P=.0001){ }^{4}$ A formal economic analysis of these findings estimated benefits (reductions in unnecessary expenditures) and costs of the intervention and considered stability of effects over time, use of substitute medications, targeting of high prescribers, and quality effects. ${ }^{6}$ The data indicated that an operational-scale program would produce savings two to three times greater than the costs of mounting such a program, without counting improvements in the quality of care. A follow-up analysis ${ }^{7}$ indicated that while physician characteristics such as age, 
board certification, and specialty did not affect response to the educational intervention, a second reinforcement visit substantially increased compliance with prescribing recommendations. Other controlled studies also have documented the effectiveness and receptivity of physicians to face-to-face counseling. ${ }^{5.10}$ This article discusses the principles and techniques of such approaches to physician behavior change.

The prescribing of drugs has served as a useful model for studying ways of improving the accuracy of physician decision making. Problems of misutilization of drugs stem from many sources, only some of which relate to the pharmaceutical industry. ${ }^{5}$ Nonetheless, the industry's marketing strategies may serve as an instructive model (both good and bad) for those interested in improving the rationality of clinical decision making. Detailing, the promotional activities of pharmaceutical company sales representatives, accounted for more than half of the estimated $\$ 3$ billion spent annually on promotion by US pharmaceutical companies in the early 1980s (Wall Street Journal. May 25, 1984:31, 49). ${ }^{11}$ Pharmaceutical representatives have been operating for more than 100 years and number about 28000 in the United States alone (Wall Street Journal. May 25, 1984:31, 49), ${ }^{12}$ or approximately one representative for every 10 office-based practitioners. ${ }^{13}$ At least $\$ 5000$ is spent per physician each year in support of detailing activities, excluding journal and direct mail advertising expenditures (Wall Street Journal. May 25, 1984:31, 49). ${ }^{11-13}$ The detailer/physician ratio is even higher in some other western countries, approximating 1:3 in Brazil and 1:4 in Mexico. ${ }^{14}$

One form of evidence for the effectiveness of these traveling personnel is that pharmaceutical companies continue to invest such large sums of money in this approach, based on their own costbenefit calculations. Several studies indicate that for many physicians, the detailer is generally the first source of information about new therapies. ${ }^{15}$ Indeed, even when commercial messages on product efficacy differ markedly from objective, scientific sources of information, the beliefs concerning several drugs of a large, randomly selected sample of primary care physicians corresponded more closely to the commercial information. ${ }^{16}$ Despite the fact that detailers shape so much prescribing behavior, there is little in the scientific literature about the techniques or approach of these representatives and how they might be adapted to reduce inappropriate prescribing. The few studies that do exist ${ }^{14,17}$ simply describe the broadly defined components of sales presentations, as derived from survey information.

The following analysis of common techniques and principles employed by such change-agents are based on indepth interviews with and videotapes of former pharmaceutical representatives, other written accounts of the detailing process, and our own experience in mounting several trials of "public interest detailing" in five states to reduce excessive or inappropriate prescribing. ${ }^{47,10}$ As discussed below, these techniques are also based on research in the fields of adult learning, diffusion of innovations, and persuasive communication.

\section{BEHAVIOR CHANGE STRATEGIES}

The effectiveness of the commercial detail visit is the result of more than 100 years of sales experience. Generally lasting less than 10 minutes, the presentation is likely to contain several effective strategies for behavior change that serve to reinforce and complement one another. ${ }^{18,19}$ Some similarities exist between pharmaceutical marketing goals and several objectives of nonprofit organizations. For example, clinical department chairpersons, quality assurance staff, and health care administrators and payers would like to encourage prescribing behavior that would contain costs without sacrificing quality of care and, ideally, would improve it. In previous studies the use of inexpensive but effective antibiotics has been promoted to replace costly cephalosporins in the treatment of uncomplicated infections ${ }^{4,6,7,9}$; the use of potentially dangerous antibiotics to treat minor infections in ambulatory practice has been curtailed (eg, chloramphenicol for viral upper respiratory tract infections ${ }^{9}$; and safe and effective over-the-counter analgesics, such as aspirin, have been substituted for less effective and potentially problematic prescription drugs such as propoxyphene. ${ }^{6}$ Other interventions have focused on the way a drug is prescribed; for example, certain effective drugs are prescribed too frequently or in excessive dosages, causing unnecessary risks of adverse drug reactions and increased costs. ${ }^{20,21}$ While important differences exist between pharmaceutical marketing and medical education or quality assurance, there is reason to believe that many of the techniques described below could be adapted to such purposes. Our goal is to identify those aspects of detailing that can be put in the service of supporting the physician in making better therapeutic decisions, while leaving aside any techniques that might be manipulative or serve only to increase sales of a given product.

\section{Defining Specific Problems and Objectives}

A key first step in any program to influence clinical decision making is to define the area(s) to be addressed and the specific behaviors to be encouraged or discouraged. Such agenda setting is more straightforward in the pharmaceutical industry, where the fiscal "bottom line" is, by definition, the outcome of concern and increasing sales of specific branded products is the means toward that end. Sponsors of other progams face more complicated choices. For a nonprofit health maintenance organization, employer, or insurer responsible for all aspects of medical care, the outcome of concern may be the highest possible quality of care at the lowest possible cost-goals that may conflict and that often cut across multiple categories of service (eg, drugs, hospitalization, and physician visits may all be affected by use of histamine antagonists). It therefore is necessary to begin by identifying the specific cases of practice that are of highest concern in terms of quality and/or cost and to design a program that will target these decisions initially, specifying clear alternatives to be encouraged. For example, Ray et $\mathrm{al}^{22}$ used Medicaid claims data to identify inappropriate prescribing of tetracycline to children by general practitioners in Tennessee. Subsequent educational efforts focused on the objectives of reducing this practice as much as possible among targeted groups due to the risk of permanent discoloration of developing teeth and substituting safer antibiotics for this population. A secondary (but less measurable) objective was to reduce prescribing of any antibiotics for simple upper respiratory tract infections.

\section{Market Research}

One of the most important lessons that can be derived from pharmaceutical marketing strategy is the need to understand the motivations that underlie physician use of a particular product. One failure of traditional continuing medical education has been the assumption that the transmittal of rational information alone, independent of how it is provided, will predictably result in improved clinical decisions. ${ }^{3}$ While the provision of new knowledge and information may be sufficient in some cases, considerable research has made apparent the need to consider other "nonscientific" factors such as attitudes toward particular diseases or patients, habits, peer influence, patient demand, time 


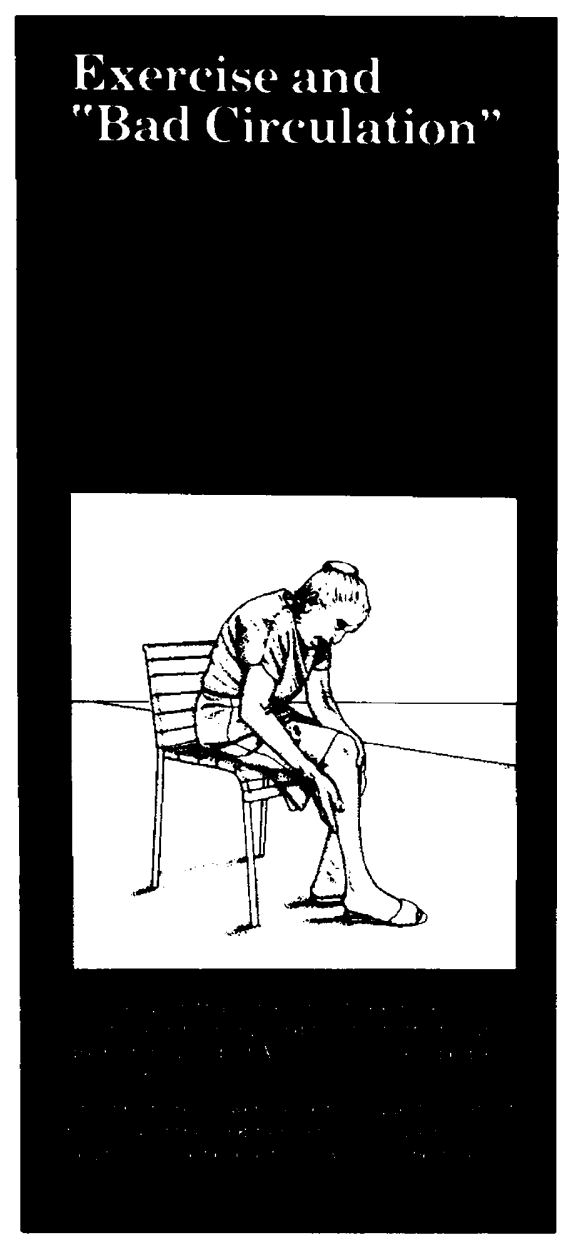

Fig 1. - Patient education material designed to reduce patient demand for vasodilators for claudication. Space for an "exercise prescription" is provided inside.

constraints in busy office practices, and economic incentives as prerequisites to the design of educational messages. ${ }^{5,23-26}$ For example, providing more information on the therapeutic efficacy of aspirin may be irrelevant to the physician who prescribes prescription analgesics primarily in response to patient demands.

Several approaches can be used to determine physician motivations for their therapeutic decisions, including focus group interviews, surveys of prescribers, and ongoing communication between detailers/educators and physicians. In focus group interviews, ${ }^{26}$ the market researcher assembles a small group of consumers (in this case, physicians) and attempts to stimulate a frank and open discussion of the important motivations for choosing particular products over others. On one level, an attempt is made to identify the major product characteristics (eg, efficacy or safety) that physicians value in their choice of similar products as well as physician perceptions of the comparative advantages and disadvantages of recommended vs competitive products. These factors eventually became major messages to communicate in face-toface details and printed advertisements (eg, the relative efficacy of one product over another, patient convenience, side effects profile, and so on).

If the facilitator is sufficiently skilled, he or she may discover some key nonclinical motivations that might otherwise remain hidden owing to their negative social or ethical tint (eg, prescribing tranquilizers to quiet demented elderly patients at the request of nursing home staff). Practice-driven motivations may cause many physicians, although fully aware of the pharmacology involved, to use marginal therapies because of patient demand factors or intentional use of active placebos. ${ }^{23}$ For this sizable group, an intervention aimed only at presenting efficacy data would yield minimal results. In our prior work, we instead developed a set of "patient management strategies" and education directed at the patient (Fig 1) to help these physicians to cope better with inappropriate requests.

The focus group approach may fail if the group of physician-volunteers (or paid consultants) sampled is not generalizable to the larger group of practitioners. To avoid this problem, several such groups are convened and larger, structured or unstructured surveys of more representative samples of target physicians are conducted before development of program content. Thus, fitting the relevant information to the values, attitudes, and beliefs of practicing physicians is an ongoing task both in defining the general content of communications in the planning stage and in the process of one-on-one education.

\section{Establishing Credibility}

Establishing and maintaining a credible identity is an essential ingredient in effective communication. In the pharmaceutical industry, credibility is sought by reference to prestigious clinical research centers that evaluated the drug and journals that reported the research. According to representatives we interviewed, the "aura" surrounding identification with clinical trials at such research centers may contribute as much to adoption of the drug as the scientific aspects of the studies. Pharmaceutical companies also sponsor scientific symposia for practicing physicians to convey product-specific information and to enhance the academic image of the company and its representatives, although data suggest that the content of such symposia occasionally may be colored by product sales mes- sages. ${ }^{27,28}$ Physician awareness of the profit motive and its potential impact on the objectivity of promotional messages presents a formidable obstacle for commercial representatives.

Sponsorship of educational outreach programs by neutral professional groups represents a significant advantage for "nonprofit" detailers. Two trials of face-to-face prescribing education utilized the imprimatur of respected medical organizations, a state medical society and a medical school drug information program. ${ }^{4,9}$ Such unbiased organizational identities were an important factor in achieving high rates of physician acceptance of the personal visits (92\% of physicians randomized to this group agreed to meet with the medical school-based "detailer"). Another important aspect of both programs was their utilization of academically based educators bringing the latest clinical findings of importance to the physician's doorstep. In another setting, the teaching hospital, credibility also can be demonstrated through identification with expert consultants (eg, antibiotic use guidelines approved by the infectious disease service). ${ }^{20}$

\section{Targeting 'High-Potential' Physicians}

Pharmaceutical sales representatives often prioritize their sales calls in relation to the magnitude of potential sales to individual physicians. ${ }^{29}$ These determinations are made through company profiles of physicians' previous prescribing patterns and other data on physician specialties and interests. Thus, a representative can maximize his potential sales per hour of effort by spending the most time with physicians whose total prescribing volumes are high enough to yield potentially high sales of the detailer's products or with physicians who are opinion leaders. Similarly, from a noncommercial standpoint, it makes no economic sense to blanket all physicians with face-to-face interventions when many of these physicians do not prescribe either inappropriately or in high enough volumes to yield substantial savings or improvements in care.

In previous controlled studies of university-based pharmaceutical education for community physicians, ${ }^{4,6,7,9} \mathrm{mod}$ erate- to high-volume prescribers of target drugs were identified using data from the Medicaid Management Information Systems in five states. While physicians reduced excessive prescribing to the same degree regardless of baseline levels of use, the benefit/cost ratio was the highest (approximately $3: 1$ ) in the group with the highest initial 
volume of target drug use. ${ }^{6}$ As hospitals, health maintenance organizations, and other health care organizations continue to develop computerized systems to track resource utilization on a physician-specific basis, it will become increasingly practical to identify physicians with particular utilization problems and present them with focused educational interventions. However, in the above studies these data were not used on an individual basis to feed back information indicating that particular physicians were operating outside of established norms. Surveillance and feedback of this sort is another approach that may work best in certain settings with established lines of authority (eg, teaching hospitals and staff model health maintenance organizations).

\section{Involvement of 'Opinion Leaders'}

A key pharmaceutical marketing strategy is to identify and involve local physician opinion leaders: those individuals who tend to be early adopters of pharmaceutical innovations and important and respected sources of influence for other physicians in their communities. Previous research by Coleman et $\mathrm{al}^{15}$ documented that a relatively small proportion of physician leaders are the most integrated into the medical information network and are also the most likely to be extremely influential persuaders of other, less-integrated physicians. Through these informal social networks, a "contagion" response is seen after adoption by the opinion leader, aided by the pharmaceutical representatives who may refer to these respected peers in their own detailing of other practitioners. The involvement of such opinion leaders in the design and implementation of quality of care or cost-containment educational interventions can also increase their effectiveness. Stross and Bole ${ }^{30}$ observed that surveys of community physicians could easily identify the most educationally influential physicians. These individuals were subsequently enlisted in a program to upgrade their colleagues' arthritis treatment decisions during informal "teachable moments," when their advice was being sought on related clinical problems.

\section{Two-Sided Communication}

Research has also shown that "inoculation against counterarguments," or presenting both sides of an issue, aids learning, particularly in situations where the receiver is knowledgeable about counterarguments. ${ }^{31}$ If detailers completely discount the positive attributes of an alternative product or thera- peutic approach, their credibility may be damaged and physicians may even feel offended that their beliefs and experiences were treated as invalid. Instead, the detailer is likely to briefly acknowledge the physician's reasons for using the competitive drug, often elicited by asking him. However, he will then deemphasize them in comparison with the advantages of his company's product. For the same reason, the detailer may briefly mention the disadvantages of the drug he is promoting - a message probably communicated already by the competition in any case. The same principle applies to nonprofit educational efforts. For example, in our attempts to persuade physicians at an urban teaching hospital to substitute gentamicin when appropriate for tobramycin, we learned that physicians believed the unsubstantiated marketing claim that tobramycin was less nephrotoxic than gentamicin. Rather than ignoring this important issue (or waiting for physicians to bring it up), we actively acknowledged the controversy and provided literature references that supported the alternative conclusion of no meaningful difference in nephrotoxicity. This process was accomplished in a tactful manner that did not excessively criticize these misperceptions.

\section{Promoting Active Learner Involvement}

Successful behavior change often is dependent on the ability of the educator to relate the message (or product) to the beliefs, needs, values, and interests of the individual physician. Thus, the attempt to engage the physician in twoway communication is an important way of building a physician-specific presen tation $^{32}$ at the same time as it increases the involvement of the physician in the interaction. For example, asking the physician why he or she uses a given drug makes it possible to identify and then target relevant motivations and clinical circumstances as well as to gauge the strength of their beliefs. ${ }^{5}$ In the commercial setting, this also makes it possible for manufacturers to use detailers as sources of marketing information, particularly in determining reactions to products soon after their release to the market. ${ }^{25}$ However, detailers are careful not to overquestion physicians, as this may lead some physicians to feel that their time is being wasted or, worse yet, that the detailer is trying to test or manipulate them. ${ }^{19}$ A sales-maximizing version of some of these principles is embodied in an article entitled "Credibility: The Key to Long-term Success," which appeared in a publication for pharmaceutical sales personnel ${ }^{33}$ :
Logical, meaningful questioning is an excellent way to give you credibility and to get the physician into a pattern of dialogue and a mindset towards responding positively to a closing challenge. Probing will get the physician to assimilate the information and require him to actively follow your thought direction. As he answers your questions, his thought will begin to crystallize. Remember, a person does his best listening when he is talking.

Similarly, a long history of research and practice in the field of adult learning has suggested that stimulating learner involvement through interaction achieves a higher likelihood of attaining educational and behavioral objectives as well as greater satisfaction. ${ }^{34}$ Our educational detailers were also trained to ask physicians, during both initial and follow-up visits, how they and their patients reacted to prescribing recommendations. These queries often led to identification of correctable obstacles. For example, discovering that some physicians used propoxyphene as an analgesic because of a lack of awareness of its risk/benefit attributes made it possible to tailor educational materials to target these knowledge deficits.

\section{Repetition and Reinforcement}

Repetition of a few major points is another technique often ignored in conventional continuing education that aids in memory retention and promotes behavior change. ${ }^{35,36}$ In a commercial detailing visit, a few principal advantages of the product are likely to be repeated several times during the detailing visit; the product name itself is further imprinted in the physician's mind through gifts from the manufacturer and advertisements with product identification. While such approaches can be carried to trivial extremes, there is some value to such mnemonic devices. For example, one "giveaway" we considered (but never adopted) for our early study was a free sample kit with the label "The Best Antibiotic Therapy for Viral Upper Respiratory Infections" emblazened over a blister-pack whose unit-dose cells were all empty. Rationale and evidence for these claims would appear on the back of the package. This principle of concentrating on a small number of important messages is based on an understanding that educational interchanges successfully transmit but a few points, no matter how complex the messages being sent. This is equally true with physicians, who have a hard enough time keeping up with the clutter of information deluge in a rapidly changing medical practice. Attempting to communicate too many or complex messages often will fail to achieve retention of the most important points. Graphic 
support with headlines, diagrams, and photographs is an important component, exposing the physician to visual as well as verbal presentation of the main points.

Feedback of improved behavior with reinforcement is another central component of effective detailing techniques that can be used by noncommercial drug information programs. Reinforcement can occur when physicians discuss their experiences with implementing recommended changes in prescribing behavior during follow-up visits. Detailers can verbally encourage and applaud their successes as well as discuss problem cases and their resolution (eg, patient demand). This principle is corroborated by data that suggest that a reinforcement visit was associated with a twofold increase in the change in prescribing behavior in an educational experiment.'

The commercial detailer may encourage the physician to "try out" the product on his patients and to report back his or her experiences at a subsequent visit, often facilitating this with free samples. If these experiences are positive, further discussion and positive reinforcement of the product ensue. However, it is easy for such a "case study" approach to cross over into pseudoscience. Some pharmaceutical representatives will pursue this strategy further by inviting the physician to conduct a "study" of the product in his or her own practice by giving several patients the promoted drug to compare with others who are taking alternative treatments. In a description of a day spent with a successful drug representative reported in the Wall Street Journal (November 8, 1982:1, 25), a physician was encouraged to conduct his own small-scale "clinical trial" comparing one company's new nonnarcotic analgesic with other pain medications in patients: "Try it, compare it for yourself, you'll like it better." This technique can set up an opportunity to reinforce "positive clinical experiences" (possibly due to placebo effects) in subsequent visits. Despite scientific invalidity of such nonblinded, smallscale trials in nonrandomized samples of patients, this approach purports to elevate the office physician's status to the level of clinical researcher, with all of its positive connotations. Through the drug to be marketed, the physician's observations are equated with "science," further validating both the physician and the drug.

In addition to such suspect approaches, commercial detailers often employ incentive strategies to reinforce desired behavior. ${ }^{37}$ These incentives are directed to all the actors involved: nurses or

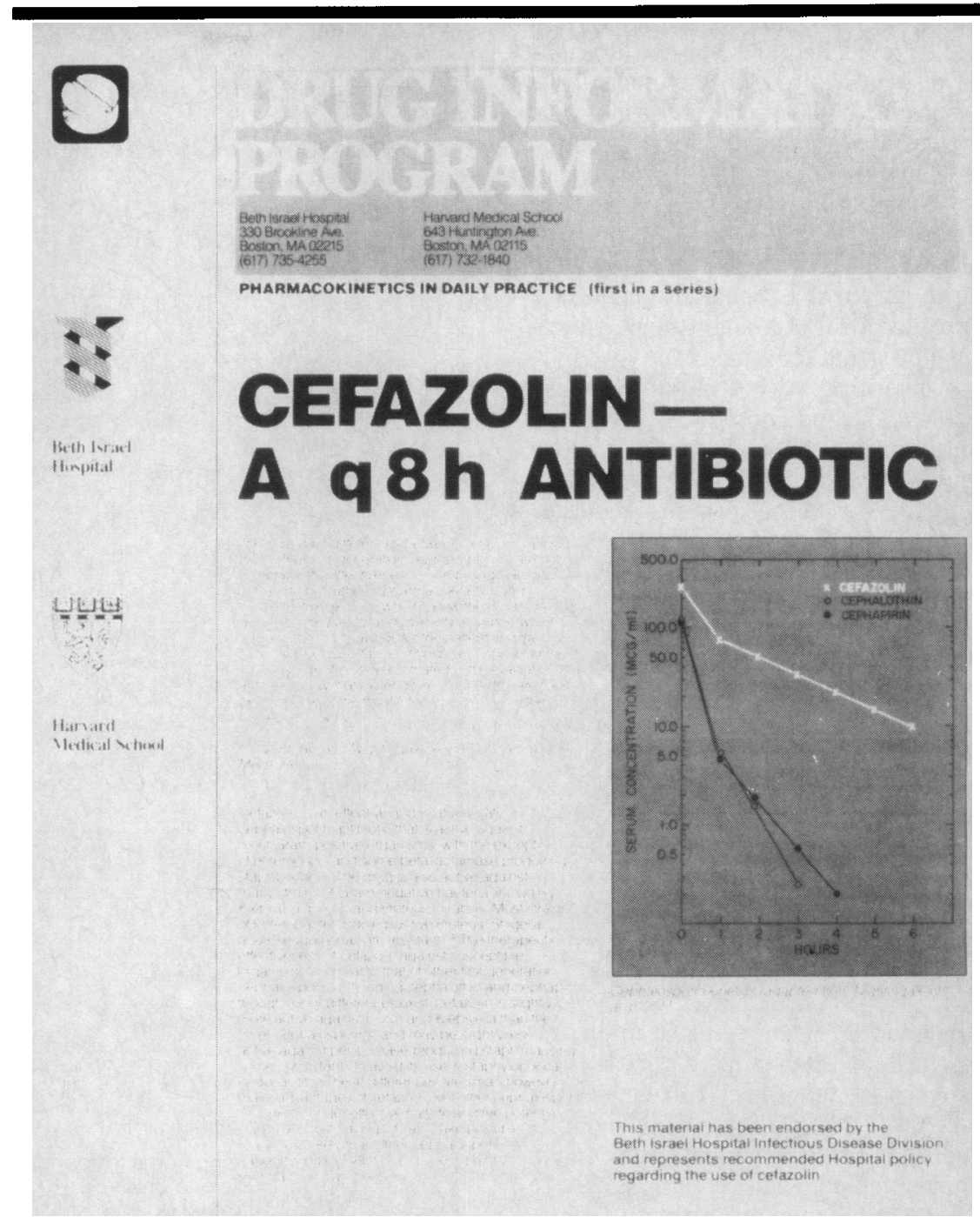

Fig 2. - Educational material used in changing prescribing habits of a cephalosporin antibiotic. Pharmacokinetic considerations were emphasized over cost issues.

receptionists are given gifts to gain access to the physician; physicians are given both gifts and free samples of the drug; patients receive both samples and educational pamphlets, also donated by the detailer. One particularly offensive use of incentives was the recent campaign by Ayerst, New York, NY, to promote use of its brand of $\beta$-blocker by offering physicians "frequent prescriber bonuses" for each patient prescribed the product for whom a small reporting form was completed. These could then be traded in for free air travel in the United States and to the Caribbean.

\section{Brief Graphic Print Materials}

Recent comprehensive reviews of studies that evaluate a wide variety of mailed continuing educational materials, including prescribing guidelines and protocols, drug bulletins, commercially prepared brochures, and two-sided "unadvertisements," have produced little or no evidence supporting their effectiveness in changing practice patterns when used alone. ${ }^{5,10}$ Nevertheless, well-illustrated materials that emphasize the main clinical recommendations in a straightforward way are important adjuncts to face-to-face education that can be mailed, posted, or inserted in patient charts as well as used as a visual device during detailing visits. Figure 2 gives an example of such an educational pamphlet used at Beth Israel Hospital, Boston, Mass, to reduce incorrect use of the antibiotic cefazolin. ${ }^{20}$ The front cover of the monograph supports the prescribing change message in both headlines and graphics; in addition, the credibility provided by support of hospi- 
tal experts and references to clinical studies published in respected journals are also presented prominently. It is essential to pilot-test materials with physicians who are similar to those in the planned audience to be certain that the content is actually received as intended.

Figure 3 presents the front cover of one of six unadvertisements used in a controlled trial of a face-to-face educational program to reduce excessive psychoactive drug use in nursing homes. The headline and photograph promote a gentle touch and "tucking in" of elderly residents at bedtime as an alternative to sedative use. On the reverse side, other practical strategies for promoting sleep are emphasized, such as avoiding daytime caffeine and napping, and increasing exercise and mobility. It also encourages more careful selection and dosing of sedatives if they are used. Thorough references to the literature are included. When such graphically illustrated data are referred to in face-toface sessions they can provide an interesting and salient respite from verbal presentations and also involve the prescribing physician in two-way communication.

\section{Offering Practical Alternatives}

Behavioral science research in numerous domains documents that it is far easier to get a subject to relinquish a behavior if an alternative behavior is proposed as a replacement, rather than simple inaction. Thus, it is important to offer the prescriber an alternative to the practice being discouraged-either a more rational medication choice or a nonpharmacologic alternative. Pharmaceutical representatives ensure that local pharmacies stock the alternative drug recommended to replace specific products prescribed by physicians. Similarly, it is important that academic detailing programs consider the practicality and availability of other treatments to replace targeted drug therapies. Nondrug alternative behaviors, in particular, may be more difficult to achieve if they require more time to implement. Unfortunately, it may be easier and more convenient for the busy physician to prescribe a benzodiazepine than to engage in a counseling session concerning the patient's family problems. On the other hand, encouraging patients with peripheral vascular insufficiency to take short walks was a reasonably actionable alternative to use of "peripheral vasodilators" prescribed for this condition. ${ }^{4}$ To help facilitate this behavior, a patient education pamphlet was prepared as a physician "prescription" of a specific exercise program, which

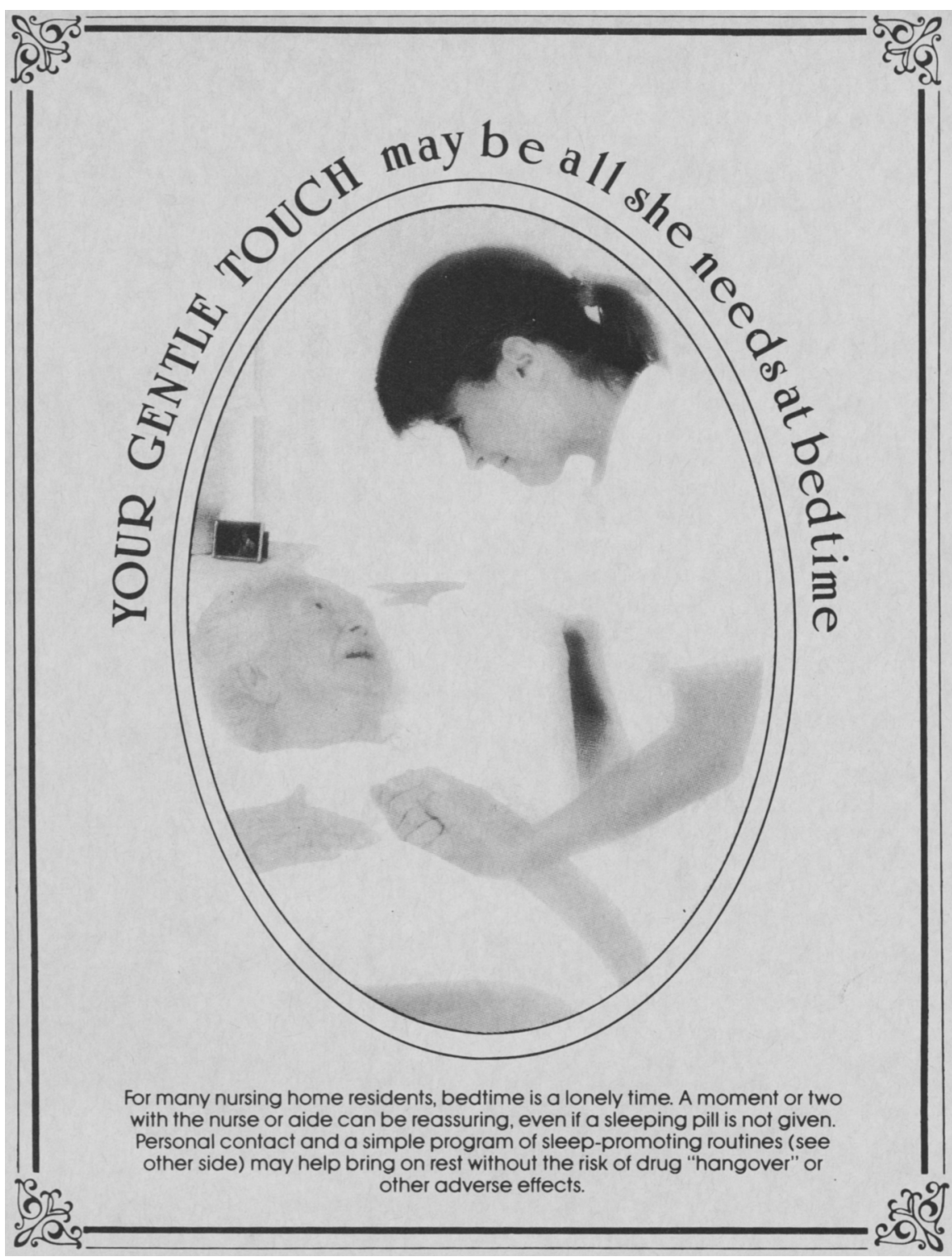

Fig 3.-Cover side of "unadvertisement" encouraging nursing home staff to substitute gentle touching and reassurance of elderly residents at bedtime for sedative use.

could be tailored to the patient's physical condition (Fig 1). For this approach to be most effective, there should be no financial disincentives to the patient that act to discourage alternative treatments. For example, overuse of expensive prescription analgesics may be difficult to reduce in a Medicaid program that does not reimburse for recommended over-the-counter alternatives such as aspirin or acetaminophen.

\section{Selection and Training of Academic Detailers}

According to the pharmaceutical marketing literature, commercial detail people are selected on the basis of both science background and potential for sales, ${ }^{38}$ although in practice the latter factor often predominates. There is no standard requirement for any science background, and often none exists. Training is a crucial element in successful pharmaceutical marketing; it is also the most carefully guarded. Hemminki and Pesonen, ${ }^{14}$ in a survey of pharmaceutical representatives in Europe, reported that the mean length of training time before commencing detail work was 14.3 weeks. This was divided between sales techniques and a segment on basic medical sciences and pharmacology. Closed-circuit television and role playing are common elements of training used to perfect presentation styles. In addition, fledgling representatives may spend some time trying out their presentations on groups of physicians. This approach is particularly useful in increasing the representative's ability to answer questions convincingly and to tailor the presentation to the par- 
ticular style of the physician. Fair trade and advertising laws are emphasized as they apply to the presentations.

Management control and feedback to detail people are carried out principally by district sales managers on the basis of ongoing communications from detailers, including information contained in required call reports as well as reports of sales from pharmacies and in hospitals. ${ }^{38}$ Since representatives are generally responsible for product sales in particular geographic regions, companies can track the amount of a given medication sold in those areas to monitor representatives' sales performance. The sales manager is also the key person in providing emotional support to detail people. Although most representatives are salaried, the majority also receive incentives for greater sales through commissions and bonuses.

Based on reports in the medical marketing literature, ${ }^{13}$ most pharmaceutical sales representatives probably make between three and eight physician contacts per day. The contact time per visit varies enormously, but an average of 5 to 8 minutes is a reasonable estimate of average physician exposure time. ${ }^{13,19}$ Because of this limited time, most representatives rarely attempt to promote more than two or, at most, three products during one visit. One product usually represents the major topic to which most of the representative's time is committed during the visit, with a secondary drug covered "on the way out the door."

In noncommercial community programs, studies have documented the effectiveness of clinical pharmacists both with $^{4}$ and without ${ }^{39}$ doctoral-level training as well as consultant physicians. ${ }^{9}$ Both pharmacists and specially trained physicians (eg, infectious disease specialists) have been used in hospitals more study is needed, however, on the comparative cost-effectiveness of various personnel for particular problem areas. Doctoral-level clinical pharmacists who were primarily junior faculty in schools of pharmacy have been shown to be effective as part-time, academically based detailers. ${ }^{47}$ Because of their previous training in pharmacology and drug information, only about 2 days of formal training was necessary for a program targeting three drugs. This followed self-study of a training manual covering important clinical issues, important principles of communication and persuasion, and major recommendations concerning the target drugs and their alternatives. In the training, videotapes were shown of a former pharmaceutical representative detailing the target drugs and their alternatives to a physician-researcher (J.A.) who sequentially acted the role of a resistant and hostile physician, an indifferent physician, and a receptive physician.

Following this, approximately a half day was spent practicing on one another, with videotaped feedback. When the pharmacist-educators and investigators were satisfied that all trainees were performing adequately, they pretested their presentation on randomly selected community physicians. These encounters were discussed by telephone with the project manager before actual detailing of study physicians began. In general, these initial experiences indicated that physicians were more receptive than was expected based on the experiences of commercial representatives.

After every physician visit, detailed encounter forms were completed to assess physician receptivity, problems encountered, methods of overcoming obstacles, call records, exposure times, etc. These were reviewed periodically by the project director (S.B.S.) to attempt to correct particularly difficult problems experienced by some detailers. We found that the clinical pharmacists needed only a minimal amount of training and supervision to perform adequately in this function. This success was evidenced by the prescribing data outcomes: physicians reduced target drug use by $14 \%$ compared with controls after only two brief visits $(P=.001) .^{4}$

\section{COMMENT}

The long-standing effectiveness and growth of pharmaceutical detailing in recent decades illustrate that considerable change in physician prescribing practice is possible without regulatory interventions. The behavioral science literature and an increasing number of field studies indicate that a number of important principles of adult learning and persuasion may be adaptable to noncommercial programs designed to improve clinical decision making. ${ }^{5,10}$ This is particularly important at a time when powerful new agents are available that have real toxic potential as well as unique therapeutic effectiveness (eg, isotretinoin). Regulation can ensure that drugs with unacceptable risk/benefit relationships are not permitted to be used, but no current regulatory apparatus can ensure that marketed drugs are prescribed intelligently. It should be possible to take the best of these educational approaches and put them at the service of optimal care, while leaving behind any techniques that are not in keeping with the spirit of professionally based continuing medical education.

For example, one important structur- al aspect of the commercial setting, but not generally used in the not-for-profit setting, is the provision of financial incentives that reward pharmaceutical representatives who achieve major prescribing changes that result in high sales of their company's products (Fortune. October 1972:99-102). From the perspective of many physicians, such financial incentives probably reduce the detailer's credibility and the perceived objectivity of his claims concerning product efficacy. In fact, these incentives have, on occasion, led to misinformation by overzealous detailers. ${ }^{27,40-42}$ This may be one reason that physicians thus are reluctant to admit that their prescribing decisions are influenced by commercial representatives. ${ }^{16}$

The principles embodied in this approach also conform with research conducted in the more general field of adult education. For example, one synthesis of this literature identified five conditions of adult learning: motivation to change, active involvement of the learner, relevance to past experience, feedback, and an informal atmosphere. Similarly, the extensive literature on patient compliance also documents the effectiveness of face-to-face educational interactions and the general failure of printed materials when used alone. ${ }^{44}$ This is particularly sobering in view of the recently legislated "practice guidelines" initiative that will be sponsored by the US Department of Health and Human Services and is intended to improve the use and outcomes of common medical practices nationwide. If such guidelines are not well integrated into formal and informal person-to-person educational programs they may not have any practical value. In coming years, it is likely that computer-based decision support systems will become sophisticated and widespread enough that some (but not all) of the interactions described above will be done electronically. However, such capacity is not likely to be available in most practice settings in the immediate future.

Some may argue that restrictions and regulations, rather than education, are simpler and more effective strategies for improving prescribing practice. In fact, restrictive hospital formularies are an effective means of reducing improper use of some medications. However, for many medications the problem is misuse of an otherwise effective agent (eg, antibiotics). Removing access to the drug through a restrictive formulary or reimbursement restrictions cannot address this issue. Further, drug restrictions are not practical without effective sanctions and enforcement. In addition, no extensive literature exists on the ef- 
fectiveness of drug restrictions in community settings, and the few extant studies suggest that restrictions of one drug can lead to generally inappropriate use of substitute medications. ${ }^{5,45}$ Educational approaches thus are more flexible and adaptable in influencing most realworld clinical decisions that do not fall into neatly defined categories of correct and incorrect practice.

The cost of new therapies is increasing sharply at the same time that pressure is escalating to control health care costs. A small but important body of

\section{References}

1. Soumerai SB, Avorn J, Ross-Degnan D, Gortmaker S. Payment restrictions for prescription drugs under Medicaid: effects on therapy, cost, and equity. $N$ Engl $J$ Med. 1987;317:550-556.

2. Lurie N, Ward NB, Shapiro MF, Brook RH Termination from Med-Cal: does it affect health? $N$ Engl J Med. 1984;311:480-484.

3. Haynes RB, Davis DA, McKibbon A, Tugwel P. A critical appraisal of the efficacy of continuing medical education. JAMA. 1984;251:61-64.

4. Avorn J, Soumerai SB. Improving drug-therapy decisions through educational outreach: a randomized controlled trial of academically based 'detailing.' N Engl J Med. 1983;308:1457-1463.

5. Soumerai SB, Avorn J. Efficacy and cost-containment in hospital pharmacotherapy: state of the art and future directions. Milbank Mem Fund $Q$. 1984;62:447-474.

6. Soumerai SB, Avorn J. Economic and policy analysis of university-based drug 'detailing.' $\mathrm{Med}$ Care. 1986;24:313-331.

7. Soumerai SB, Avorn J. Predictors of physician prescribing change in an educational experiment to improve medication use. Med Care. 1987;25:210221.

8. Soumerai SB. Improving the quality and economy of in-hospital prescribing: getting more for less. Med J Aust. 1988;149:574-576.

9. Schaffner W, Ray WA, Federspiel CF. Improving antibiotic prescribing in office practice: a controlled trial of three educational methods. JAMA 1983;250:1728-1732.

10. Soumerai SB, McLaughlin T, Avorm J. Improving drug prescribing in primary care: a critical analysis of the experimental literature. Milbank $Q$. In press

11. Rucker TD. Drug information for prescribers and dispensers: toward a model system. Med Care. 1976;14:156.

12. Rx detail forces will not keep pace with MD growth during next six years, SRI predicts; MS \& $\mathrm{D}$ and $\mathrm{SK} \& \mathrm{~F}$ are increasing detail forces against trends. $F-D$-C Reports. 1982;44:3.

13. Roseman $E$. How to gain your fair share of sales time. Med Market Media. February 1985:2428.

14. Hemminki $\mathrm{E}$, Pesonen $\mathrm{T}$. The function of drug company representatives. Scand $J$ Soc Med. 1977;5:105-114. research and practice has begun to emerge based on the concept of academic detailing that may present a rational response to these pressures. Such educational outreach activities by universities, medical centers, and professional associations are increasingly proposed or being implemented under the sponsorship of hospitals, public-sector programs, health maintenance organizations, and other insurers. The applicability of this approach offers promise to other areas beyond prescribing, such as the use of blood products, laboratory

15. Coleman JS, Katz E, Menzel H. Medical Innovation: A Diffusion Study. Indianapolis, Ind: Bobbs-Merrill Co Inc; 1966

16. Avorn J, Chen M, Hartley R. Scientific vs. commercial sources of influence on physician prescribing behavior. Am J Med. 1982;73:4-8.

17. Hemminki $\mathrm{E}$. Content analysis of drug-detailing by pharmaceutical representatives. Med Educ. 1977;11:210-215.

18. Roseman E. Make sure your sales force delivers the right message. Med Market Media. September 1985:90-95.

19. Roseman E. Checking the scorecard. $\mathrm{Med}$ Market Media. October 1985:40-44.

20. Avorn J, Soumerai SB, Taylor W, et al. Reduction of incorrect antibiotic dosing through a structured educational order form. Arch Intern Med. 1988;148:1720-1724.

21. Buchwald D, Soumerai SB, Vandevanter $N$, Wessels MR, Avorn J. Effect of hospitalwide change in clindamycin dosing schedule on clinical outcome. Rev Infect Dis. 1989;11:619-624.

22. Ray W, Federspiel CF, Schaffner W. Prescribing of tetracycline to children less than 8 years old: a two-year epidemiologic study among ambulatory Tennessee Medicaid recipients. JAMA. 1977;237: 2069-2074.

23. Schwartz RK, Soumerai SB, Avorn J. Physician motivations for nonscientific drug prescribing. Soc Sci Med. 1989;28:577-582.

24. Smith MC. Appeals used in advertisements for psychotropic drugs: an exploratory study. $A m J$ Public Health. 1977;67:171-173.

25. Gorzalski EJ. Use your sales force to feed back vital product launch information. Med Market Media. October 1986:1827.

26. Zelnio RB, Zimmerman JG. Match your data collection method with your research needs. $M e d$ Market Media. January 1985:51-55.

27. Opren scandal. Lancet. 1983;1:219-220.

28. Bowman MA. The impact of drug company funding on the content of continuing medical education. Mobius. 1986;6:66-69.

29. Labson D. Conversations with a detailperson: part II. Med Market Media. February 1979:16. 30. Stross JK, Bole GG. Evaluation of a continuing education program in rheumatoid arthritis. Arthritis Rheum. 1980;23:846-849.

31. Hovland CI, Lumsdaine AA, Sheffield FD. Ex - tests, and other diagnostic resources and the decision to hospitalize. In this way, improved precision in clinical decision making can present an attractive alternative to the twin extremes of unacceptable costs and unacceptable restriction.

This work was supported in part by the John A. Hartford Foundation and the National Center for Health Services Research (grants HS 03880 and HS 04933).

Figures 1 through 3 were reproduced with permission from Beth Israel Hospital, Boston, Mass

periments on Mass Communication. Princeton NJ: Princeton University Press; 1949.

32. Watts WA. Relative persistence of opinion change induced by active compared to passive participation. J Pers Soc Psychol. 1967;5:4-15.

33. Ragland B. Credibility: the key to long-term success. Pharm Rep. 1985;15:14-15.

34. Long HB. Adult Learning: Research and Practice. New York, NY: Cambridge University Press; 1983.

35. Cook T, Insko C. Persistence of attitude change as a function of conclusion reexposure: a laboratory-field experiment. J Pers Soc Psychol. 1968;9:332-328.

36. Roseman E. Open your eyes to using visual aids in selling. Med Market Media. October 1985:610.

37. Eisenberg JM. General principles: a brief overview. In: Doctor's Decisions and the Cost of Medi cal Care. Ann Arbor, Mich: Health Administration Press Perspectives; 1986:91-97.

38. Smith MC. Principles of Pharmaceutical Mar keting. Philadelphia, Pa: Lea \& Febiger; 1968:299 316.

39. Avorn J, Soumerai SB, Everitt DE, Sherman DS, Beers MH, Salem SR. Reduction of psychoactive drug use in nursing homes through 'academic detailing.' Clin Res. 1988;36:331A. Abstract.

40. Eastman M. The day the detail man talked. $A m$ Pharm. 1978;NS18:8.

41. Silverman M, Lee PR. Pills, Profits and Poli tics. Berkeley: University of California Press; 1974. 42. Darvon MD education campaign deteriorating rapidly, FDA scolds Lilly. Weekly Pharm Rep. 1980;29:4.

43. Long HB. Adult Learning: Research and Practice. New York, NY: Cambridge University Press; 1983:244.

44. Haynes RB, Wang E, Gomes MDM. A critical review of interventions to improve compliance with prescribed medications. Patient Educ Counsel. 1987;10:155-166.

45. Soumerai SB, Ross-Degnan D, Gortmaker S, Avorn J. Withdrawing payment for non-scientific drug therapy: intended and unexpected effects of a large-scale natural experiment. JAMA. In press.0C9457 